\title{
LA UNIÓN DE BREST
}

\author{
Subdiác. Alfredo Nezechuck
}

\section{Introducción}

En el año 2016, se celebraban en Roma, con una solemne Divina Liturgia Pontifical presidida por el Arzobispo Mayor de Kiev-Halych Su Beatitud, Patriarca Sviatoslav Shevchuk, los 420 años de la renovación de la plena comunión de la Iglesia Ucraniana con la Sede de Pedro, conocida como la Unión de Brest $^{1}$ firmada en Roma el 23 de diciembre de 1595 y proclamada en Ucrania en un sínodo convocado el 16 de octubre de 1596 en Brest.

Esta breve presentación no pretende agotar todos los argumentos históricos referentes a la Unión de Brest, sino tiene como objetivo hacernos conocer y compartir una parte de la historia de la Iglesia poco conocida en el occidente cristiano.

El patriarca de Antioquía Máximo IV dice: Los cristianos se amarían más si se conocieran mejor. El problema interritual entre la Iglesia de rito latino y las Iglesias Orientales no es incompatibilidad litúrgica o doctrinal sino un profundo desconocimiento, incomprensión y desconfianza, y, por consiguiente, un alejamiento recíproco. Algunos se preguntan ¿Quiénes son los ucranianos? ¿Porque no son latinos? ¿Qué diferencia hay? ¿Qué sentido tiene? Generalmente se nos considera ortodoxos (separados) o católicos de segunda categoría, o sea algo intermedio entre ortodoxos y verdaderamente católicos, que sería la Iglesia de rito latino.

El Concilio Vaticano II insiste en la necesidad de conocimientos mutuo:

Aquellos, pues, que por razón del cargo o del ministerio apostólico tengan frecuente trato con las Iglesias orientales o con sus fieles, sean adiestrados cuidadosamente en el conocimiento y práctica de los ritos, disciplina, doctrina, historia y carácter de los orientales según la importancia del oficio que desempeñan (Orientalium Ecclesiarum N6).

Para poder comprender mejor el tema a tratar se hace necesario detenernos un momento en conocer el desarrollo histórico previo a la unión

\footnotetext{
${ }^{1}$ La ciudad de Brest, anteriormente conocida como Brest-Litovsk es una ciudad de Bielorrusia, cercana a la frontera con Polonia, en la confluencia de los ríos Bug Occidental y Mujavéts, de allí recibe el nombre la unión.
} 
que tuvo la Iglesia en tierras rutenas $^{2}$. Para tal motivo presentamos una apretada síntesis histórica previa a la unión, resaltando los aspectos eclesiales y políticos más relevantes. Nos serviremos para ello de datos aportados por diversos autores.

\section{El cristianismo en tierras de la Rus-Ucrania}

Según crónicas ucranianas y extranjeras, el cristianismo en tierras de la Rus-Ucrania, tiene su origen durante los primeros siglos. Una primera noticia se refiere a la posible aparición del apóstol San Andrés en Kiev. Otra presencia de cristianos romanos desterrados se da en las colonias carcelarias de Crimea, donde el tercer Papa, Clemente Romano, murió desterrado en el año 100.

Pero la gran difusión del cristianismo se debió sin duda a la misión de los santos Cirilo y Metodio y sus misioneros que quedaron en territorios ucranios. Durante el principado de Ihor (siglo $X$ ) existía ya una comunidad cristiana en Kiev y la iglesia de San Elías. Esta difusión del cristianismo en tierras ucranias fue pacífica y sin persecuciones en oposición a lo sucedido en el Imperio Romano.

El príncipe Vladimiro, el "Grande", soberano del Estado de Kiev, otorgó un gran impulso al cristianismo con el bautismo de la Rus de Kiev en el año 988. Además de la construcción de iglesias, Vladimiro se preocupó por la instrucción y difusión del cristianismo entre la población ucrania. Ordenó la traducción de libros religiosos, mantuvo pacificas relaciones con la Europa occidental, especialmente con la Sede de Pedro. En 991 el Príncipe envió una delegación a Roma. El Papa Juan XV (985-996) y Silvestre II (999-1003), mantuvieron intercambios epistolares y de delegaciones con la Rus de Kiev.

En cuanto a los primeros Obispos y Metropolitas llegados a Kiev, es difícil determinar su procedencia. Algunos opinan que vinieron de Bulgaria, otros en cambio, de Bizancio. Ciertamente la metropolía de Kiev, dependía del Patriarcado Constantinopolitano. El primer Metropolita fue Miguel, lo siguieron Leoncio, Anastasio, Iván, Teopempt, Cirilo, Ilarión. Se nombró metropolitas para Kiev, y más tarde obispos griegos para las sedes de Chernihiv, Pereiaslav, Turiv, Bilhorod, Volodimir, Rostov, etc. Estos Obispos dependían luego del metropolita de Kiev.

En el año 1037 el príncipe Iaroslav, con respecto a la vida eclesial ucrania, dio un gran apoyo en todos los niveles: mandó construir la Catedral de "Santa Sofía", muy semejante a la de Constantinopla; también otras catedrales para los obispos, e iglesias en diversas ciudades ucranias. Uno de los hechos más importantes fue reunir un sínodo ucranio, donde los obispos eligieron al primer

\footnotetext{
${ }^{2}$ Rutenos o "pequeños rusos" para distinguirlos de los rusos propiamente. Esta denominación ha sido utilizada por la cancillería romana y polaca hasta prácticamente el siglo XX. Actualmente en la provincia de Uzhorod al sud-este de Ucrania existe la Iglesia Greco-Católica Rutena.
} 


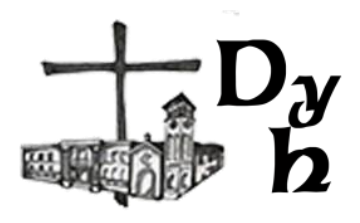

metropolita ucraniano: Ilarión. De esta manera Iaroslav, buscó impedir las injerencias de los bizantinos en la vida eclesial interna de Kiev, salvaguardando así la universalidad y particularidad de la iglesia ucraniana.

Junto al florecimiento de la vida eclesial, el monaquismo también tuvo su desarrollo en Ucrania, ejemplo de ello es el monasterio de Pecherska Lavra, cuyos fundadores fueron Antonio y Teodosio, ambos santos.

La ruptura formal de las Iglesias orientales de la comunión visible con el Obispo de Roma en 1054 fue un acto que desde muchos siglos estaba gestándose; pero a dicha ruptura no adhirió plenamente la Iglesia de Kiev como veremos más adelante.

Los motivos y causas de esta ruptura fueron los rituales de sacristía, las distintas formas litúrgicas de celebración, las mentalidades, cultura e idioma (latín y griego), oportunismo político, etc. Además se encuentran los problemas teológicos entre orientales y occidentales: la Procesión del Espíritu Santo, el Purgatorio, el Primado del Romano Pontífice, el pan (ázimo y fermentado) para la Consagración, el "Filioque", etc. (Glinka, 1986, pág. 27).

Las excomuniones lanzadas entre el Cardenal Humberto Silva de Cándida y el Patriarca bizantino Miguel Cerulario fueron la formalización de una realidad que desde siglos estaba preparándose. Desde esa fecha la Iglesia Apostólica perdía una importante iglesia: la bizantina.

Mientras la polémica continuaba entre latinos y bizantinos, la Iglesia ucrania de Kiev mantenía una vida tranquila, ajena a tensas cuestiones eclesiales. Se puede comprobar que por ciento cincuenta años, la metropolía de Kiev se mantuvo neutral y sólo a fines del siglo XI aparecieron los primeros escritos antilatinos y anticatólicos en esa ciudad, publicados por los griegos. El clero ucranio y los fieles se mantenían ajenos a la polémica. Además el Papa Gregorio VII, en 1075, aceptó bajo su protección apostólica al Estado de Kiev y envió la corona apostólica al príncipe Iziaslav. También el príncipe Vsevolod siguió manteniendo relaciones diplomáticas con el occidente católico latino. Estos y otros hechos históricos demuestran las buenas relaciones de los príncipes ucranios con Roma y Europa.

Durante el período de los Príncipes ucranios de Kiev hasta la decadencia, esa ciudad fue el centro de la cristiandad eslava. Se habían construido más de cuatrocientas iglesias y el monaquismo oriental fue el motor de la vida espiritual y cristiana del pueblo, fundándose los monasterios de Halych, Peremyshl, etc. Se tradujeron libros litúrgicos, se codificaron las primeras Leyes Eclesiales en el libro Verdad Rutena; el nivel cultural religioso ucranio de los siglos $\mathrm{X}$ y XI estaban a la altura de los centros europeos occidentales.

En el año 1274 el metropolita Cirilo se destaca por la convocación al Sínodo ucranio de los Obispos en Volodimir, donde se aprobaron doce Estatutos disciplinarios para el clero y la legislación eclesial ucrania. Suzdal, 
centro muy importante de eslavos en el norte, continuó con la política eclesial separatista, aprovechando la decadencia de Kiev por la presencia de los tártaros. Los príncipes de esta ciudad pretendían tener una metropolía, separada de Kiev, obteniéndola en 1299, cuando el metropolita griego Maksim, abandonaba definitivamente Kiev para establecer en Suzdal. Pero tampoco esta ciudad pudo gozar de un largo tiempo de paz, pues, la inmediata presencia de los tártaros hizo que perdieran el dominio Nord-oriental y en su lugar surgiría el Principado Moscovita que, con el pasar de los años, llegó a centralizar todos los territorios nórdicos en el Imperio Ruso, actual.

Tras la decadencia y destrucción del Estado de Kiev y de la ciudad misma, el centro político, comercial, cultural y religioso ucranio, se trasladó hacia el oeste, en dirección a los territorios del Reino de Galitzia. Estos territorios forman parte de la historia ucrania, aún antes del gran Príncipe ucranio Vladimiro. Desde el año 1200 los príncipes de Kiev mantuvieron relaciones con Alemania, Polonia, Hungría e intercambios epistolares con el Papa Inocencio III, (11981216), que le había ofrecido la Corona Apostólica. Las relaciones con los latinos fueron pacíficas y tolerantes en el Principado. Hacia el siglo XI existía ya un Obispo eparca ucranio en Peremyshl, y en el siglo XII en Halych, (ciudad más importante de Galitzia). En el año 1235 la ciudad de Kholm tenía también un obispo ucranio. De esta forma la Iglesia de Galitzia estaba preparándose para recibir toda la tradición ucrania, traída de Kiev. Pero la tolerancia entre latinos y ucranios en Galitzia no se mantuvo por mucho tiempo.

La situación internacional había contribuido desfavorablemente al Principado de Galitzia durante el siglo XIV. Casimiro, Rey de Polonia llevó una política militar de ocupación de los territorios ucranios. Los húngaros a su vez, ocuparon territorios galitzianos. Los lituanos tenían sus pretensiones territoriales, y por otro lado los tártaros no habían disminuido sus continuos ataques, mediante el pillaje y la destrucción. Así se llegó al año 1387, cuando el Rey polaco Casimiro, incorporó definitivamente los territorios de Galitzia a Polonia, los lituanos, la Volinia y los húngaros se llevaron su porción.

La Iglesia ucrania de Galitzia, también estaba sometida a las dificultades políticas del tiempo. En 1303, el Emperador Bizantino Androníco y él Patriarca Atanasio declararon la erección de la Metropolía de Halych, a la que pertenecían las Eparquías bizantinas de Halych, Peremyshl, Volodimiria, Kholm, Lutch y Turiv. El primer Metropolita fue el griego Nifonte.

La Metropolía de Halych no pudo permanecer independiente, pues, en 1345 no tenía ningún metropolita y pasó a depender nuevamente del metropolita de Kiev, que entonces residía en Moscú, y se había titulado metropolita de toda la Rus. En 1371, por mérito de Casimiro, Rey de Polonia, la Metropolía de Halych fue por segunda vez reconocida por el Patriarca de Constantinopla nombrando a Antonio como Metropolita de la misma sede. 


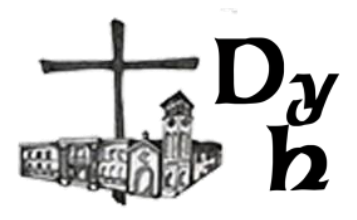

En 1470, la situación ucrania empieza hacerse difícil:

El Rey polaco Casimiro había tomado una actitud negativa hacia los ucranios, llegando hasta nombrar un lugarteniente de Rito Latino en Kiev. La actitud de los polacos hacia los ucranios, llevó a éstos a acercarse a los moscovitas, buscando establecer relaciones con los eslavos del norte (Glinka, 1986, pág. 26).

Toda esta situación política y militar que tuvo que vivir el pueblo ucranio también la vivió la Iglesia ucrania de Kiev: tuvo que sufrir también por las pretensiones rusas de querer dominar y hacer depender la metropolía de Kiev a Suzdal.

Los metropolitas de Kiev que también llevaron el título de toda la Rus fueron: Cirilo, Makcym, Pedro, Teognost, Aleksy, Cipriano, Focio, Gregorio, Isidoro (que participó del Concilio de Florencia en 1439), Gregorio II (14581473). En 1458 la metropolía de Kiev fue definitivamente dividida en dos, la "Moscovita" y la de "Kiev-Bielorrusia", siendo metropolita de ésta Gregorio. Después de Gregorio, siguieron Mysaíl, Simeón, Iona, Macario, Iosyf, losyf II, Iosyf III, Macario, Silvestre, Illia y Onisofor Divochka (1570-1589) estos metropolitas, generalmente residían en Vilna (Lituania), a veces en Novhorod o en Kiev, según que las circunstancias políticas permitieran. Hasta aquí un panorama general de la vida eclesial en Ucrania.

\section{Antecedentes de la unión de la Iglesia Rutena a la Sede Apostólica}

Al efecto describimos algunos de los hechos más singulares al respecto de las relaciones de comunión que existían entre la Iglesia Rutena ${ }^{3}$ y la Sede Apostólica según los testimonios de la historia.

Es muy cierto que en esta época el gran príncipe de Kiev reconocía expresamente la autoridad del papa, lo mismo que san Teodosio y todos sus seguidores.

Ciertamente, para el 1075 se pagaba el tributo convenido a la Santa Sede, y aun se cree que el papa Gregorio VII coronaba los príncipes de Kiev (Santos Hernández, 1978, pág. 527).

Como mencionamos más arriba el cisma entre Oriente y Occidente no afectó directamente a la Iglesia de Kiev. No existen pruebas históricas para demostrar que la Iglesia de Kiev se haya adherido al cisma separándose de Roma (Hazuda).

Indirectamente, el distanciamiento de la Iglesia de Kiev con la de Roma, se debió a dos motivos: los intereses de los rusos ortodoxos que buscaban extender sus dominios de autoridad sobre todos los ucranios, presentándose como los verdaderos defensores de la ortodoxia oriental y la prepotencia de los

\footnotetext{
3 Para esta presentación se utilizará indistintamente los términos de Iglesia Rutena e Iglesia Ucraniana como sinónimos.
} 
latinos hacia los ucranios, particularmente tomando una actitud anti-ortodoxa ${ }^{4}$ y polémica hacia las costumbres y tradiciones eslavas.

La ruptura eclesial de los bizantinos y su separación de la catolicidad no tuvo un inmediato efecto sobre la Metropolía ucrania de Kiev, que se manifestó a causa de las presiones bizantinas y rusas.

La separación de Roma por parte de la Iglesia Ucrania, más que por una ruptura formal, se produjo lentamente a través de los siglos por diversas circunstancias históricas por falta de contacto, por desconocimiento y por alejamiento. A esto contribuyeron los patriarcas bizantinos quienes nombraban para la Sede de Kiev metropolitas griegos, anti-latinos y anti-romanos y polémicos, llevando lentamente a la Iglesia de Kiev al aislamiento y alejamiento de Europa. Apuntamos algunos hechos históricos.

El primer metropolita de Kiev que rompió los lazos de unión con Roma, reconociendo ahora la jurisdicción del patriarca constantinopolitano, fue el griego Nicéforo, en el 1104. Pero en el 1147 el concilio de obispos ucranianos rompía, a su vez, con el patriarca de Bizancio, y, por mayoría de votos, concedía la dignidad metropolitana de Kiev al ucraniano Clemente Smolatycz. Se le dio la bendición con las reliquias del papa san Clemente. No duraría mucho tiempo esta situación, pues los partidarios de la Iglesia ortodoxa bizantina, ayudados por los príncipes de Suzdal, arrojarían de la sede de Kiev al metropolita Clemente, y establecerían en ella nuevamente a metropolitas griegos.

A partir de 1126 nacía el nuevo ducado de Halych a expensas del de Kiev. Conseguida la independencia política, nada de particular que buscaran asimismo la independencia eclesiástica. Desde el 1141 los príncipes o duques de Halych habían conseguido ya la erección de una metropolía propia, independiente de la de Kiev. Aunque después de la muerte del titular Antonio, no tendría metropolitas propios, a partir de la segunda mitad del siglo XIV.

Volvieron a reanudarse las relaciones con Roma, y así, en el 1245, el arzobispo ucraniano Pedro, y probablemente el metropolita de Kiev, Pedro Akerovycz, participaron en el primer concilio ecuménico de Lyon. En todo caso, no sería más que una unión efímera.

Tras las uniones fracasadas, no se había dejado de lado ese acuciante problema de la unión. Se trataría nuevamente en el concilio de Constanza (1417-1418), y luego en el de Florencia, de 1439. En el de Constanza tomó parte el metropolita de Kiev Gregorio; se puso al frente de otros 19 obispos griegos, también presentes en aquel concilio, que tenían poderes para entablar negociaciones con las autoridades romanas, y llegar incluso, si ello fuera posible, a la unión. El proyecto no tuvo éxito.

\footnotetext{
${ }^{4}$ Aquí hay que aclarar que las más de las veces la Iglesia de Roma asoció equivocadamente a las iglesias de Rito Bizantino como ortodoxas (separadas de la comunión), confundiendo el rito con el ser católico.
} 


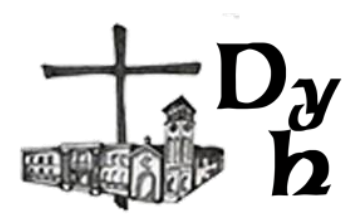

Lo que no pudo conseguirse en Constanza, se conseguiría años más adelante en Florencia, concilio al que asistía en calidad de padre conciliar el metropolita de Kiev y de toda Rusia, Isidoro.

El metropolita Isidoro llevaba a Moscú la misión específica de preparar aquella Iglesia para un entendimiento con la Iglesia de Roma, lo mismo que estaba tratando de hacer la Iglesia de Constantinopla. Sin apenas haber conocido el ambiente de Moscú, se trasladó a Ferrara en el $1437^{5}$, designado, además, representante del patriarca de Antioquía. Él, juntamente con el también célebre Bessarion, había de ser en aquel concilio uno de los más destacados campeones de la unión de las Iglesias. Al finalizar el concilio, en el que se firmó por ambas partes la unión, el propio Isidoro, uno de los firmantes, tanto en nombre propio, como en el del patriarca antioqueno, marchó a su sede de Kiev y Moscú, pasando antes por el territorio de Lituania. La unión proclamada por el metropolita Isidoro fue favorablemente acogida en Ucrania y en Bielorrusia. Tanto el clero ucraniano como los fieles todos, recibieron al metropolita con señales de respeto, sobre todo en Kholm y en Kiev. De Kiev, Isidoro se dirige a Moscú para encontrarse con el Príncipe moscovita Basilio y con la jerarquía ortodoxa rusa. El Príncipe Basilio recibió a Isidoro solamente para informarse de lo acaecido en Roma y para asegurarse que los bizantinos firmaron la Unión Católica. Después de la amplia exposición presentada por Isidoro, fue puesto en cárcel por orden del Príncipe moscovita.

A pesar de todo, esta unión no pudo echar hondas raíces en el territorio ucraniano. Hubo varias causas que influyeron en el fracaso; es que Moscú se oponía radicalmente a ella, sobre todo su príncipe Basilio, y, cosa extraña, también no pocos católicos polaco-lituanos, entre ellos el obispo latino de Vilna, Mateo. Tras una lucha de unos 60 años, fracasaría nuevamente aquella unión proclamada por Isidoro.

Gregorio II $^{6}$ (1458-1472) llegaba a Ucrania con cartas del papa para la Iglesia ucraniana. Había sido escogido por el mismo Isidoro, y consagrado en

\footnotetext{
${ }^{5}$ El Papa Martín V y su sucesor Eugenio IV hicieron todo lo que estuvo a su alcance para llegar a la unidad con los bizantinos en un Concilio Ecuménico como pedían los ortodoxos. Gracias al empeño de los dos Pontífices, los orientales asistieron al Concilio, primero en Ferrara (1437), luego Florencia. Durante las sesiones tanto los Orientales Ortodoxos, como los Latinos han discutido todas las cuestiones teológicas que existían entre las dos Iglesias. Aclaradas las dificultades, finalmente se llegó a la firma de la Bulla de la Unión Católica el 5 de julio de 1439. Todos los griegos firmaron el documento, únicamente se negó a hacerlo el Metropolita Marcos Eugenio, que, abandonando la Asamblea Ecuménica antes de su final, volvió a Constantinopla para propagar su posición contraria a la unión firmada en Florencia.

${ }^{6}$ Gregorio Mammas tuvo los siguientes títulos o nombramientos eclesiásticos: metropolita de Kiev de 1436 a 1458, cardenal de la Iglesia, primer cardenal de rito oriental, juntamente con Bessarion.
} 
Roma por el patriarca constantinopolitano, como metropolita de Kiev. El papa pedía al rey Casimiro IV que recibiera con toda benevolencia al nuevo metropolita; bajo su inmediata jurisdicción quedaban las diócesis siguientes: Kiev, Vladimir (Volhynia), Luck, Kholm, Peremyshl, Halych, Turiv, Polotsk, Smolensko y Briansk. Así, pues, también el metropolita Gregorio fue un celoso partidario de la unión, que siguió intacta durante todo su pontificado, tanto en Ucrania como en Volhynia. Aceptado, naturalmente, por la región polacolituana, fue rechazado por la parte de Moscú, cuyo metropolita Jonás, comenzaba entonces mismo a utilizar el título de metropolita de Moscú y de toda Rusia. Había, pues, desde entonces, dos metropolías en Rusia: la de Moscú, independiente incluso del patriarcado de Constantinopla, y la de Kiev para la región rutena o polaco-lituana.

Para buscar una solución adecuada, algunos obispos ucranianos y ortodoxos comenzaron a pensar en las ventajas de una nueva unión con Roma, ya que, por una parte, experimentaban el estado lamentable de sus iglesias, y por otra, querían frenar los avances del protestantismo. El proyecto de unión comenzó a discutirse en algunas reuniones secretas de los obispos rutenos con el rey Segismundo III, que se mostraba favorable a la unión por razones meramente políticas.

\section{¿Unión o reunificación?}

En año 1595 la jerarquía ucraniana, reunida en un sínodo en la ciudad de Brest, decidió renovar la plena comunión eclesial con la Sede de Pedro, elaborando un documento con 33 condiciones, para obtener una garantía por parte de Roma que no serían forzados a abandonar el rito bizantino. El acto de la unión de la iglesia en Brest no vino repentina o inesperadamente; como mencionamos hace un momento, era el fruto de muchas reuniones y conferencias por muchos años de todos los obispos de la iglesia de Kiev. Estos artículos no sólo se convirtieron en el fundamento de la relación entre las iglesias, sino que fueron formulados muy claramente para proteger la identidad de la Iglesia de Kiev.

Las primeras 11 condiciones tienen un carácter teológico jerárquico y se refieren a cuestiones de fe, Sacramentos y disciplina eclesiástica. Las doce siguientes tienen un carácter eclesial y comunitario. Las 10 restantes se refieren a temas varios de carácter más bien organizativo a nivel interno.

Estos artículos fueron redactados en tres idiomas: ucraniano, polaco y latín. Sobre la base de este documento, la Iglesia de Kiev está en comunión con la Iglesia romana. Aquí solo transcribimos algunos de ellos:

Necesitamos garantías previas de estos artículos de los romanos antes de entrar en unión con la Iglesia romana. 
15. Si en el futuro alguien de nuestra Religión quiere unirse a la Iglesia Romana, negando su propia Religión y Ceremonias, que no sea aceptado, ya que está degradando las ceremonias de la única Iglesia de Dios, ya que estando en una Iglesia, tendremos un Papa.

16. Que los matrimonios pueden tener lugar libremente entre los fieles romanos y los fieles de la Rus, sin ninguna obligación en cuanto a la religión, ya que ambos ya son una Iglesia.

19. Que los archimandritas, los higúmenos, los monjes y sus monasterios, según la antigua costumbre, estarán bajo la obediencia de los obispos de sus diócesis, pues entre nosotros hay una sola Regla monástica que incluso los obispos usan y no tenemos "Provinciales".

20. Que en el tribunal, entre el clero romano, también debemos tener dos de nuestro [clero] para cuidar los asuntos de nuestra Iglesia.

21. Que los archimandritas ${ }^{7}$, los higúmenos ${ }^{8}$, los sacerdotes, los archidiáconos y nuestro otro clero sean tenidos en la misma estima que el clero romano, y gozaren y usaren las mismas libertades y privilegios que le concedieron el rey Ladislao; deben estar exentos de todo impuesto, tanto personal como relativo a la propiedad eclesiástica, en contraste con la práctica injusta que hasta ahora ha obtenido si poseen propiedades particulares, deberían pagar impuestos sobre ellos, lo que sea justo, como lo hacen otros propietarios. Todo sacerdote y otro clero que posea propiedades eclesiásticas en los territorios de los senadores y de la nobleza están sujetos a ellas y deben obedecerlas: no deben apelar a los tribunales ni entablar disputas con los terratenientes, pero debe reconocer el derecho de patrocinio. Pero las acusaciones sobre la persona del clero y sus funciones espirituales, están sujetas solamente al obispo, y los delitos menores del clero serán castigados exclusivamente por el obispo sobre las quejas del propietario. Así, todos, clérigos y laicos, tendrán sus derechos preservados enteros e inviolables.

22. Que los romanos no deben prohibirnos tocar campanas en nuestras iglesias el Viernes Santo, tanto en las ciudades como en todas partes.

23. Que no se nos prohíba visitar públicamente a los enfermos con los santísimos Misterios, con luces y vestiduras, según nuestras rúbricas.

24. Que sin ninguna interferencia podamos ser libres para celebrar procesiones, como muchos que se requieren, en días santos, de acuerdo a nuestra costumbre.

25. Que nuestros monasterios e iglesias rusas no deberían ser transformados en iglesias católicas romanas. Y si algún católico romano ha dañado o destruido una de nuestras iglesias o monasterios, en su territorio, estará obligado a repararlo o a construir uno nuevo para el uso exclusivo del pueblo ruso.

\footnotetext{
${ }^{7}$ En la iglesia bizantina, superior de un monasterio o de un grupo de monasterios.

${ }^{8}$ Un higúmeno es un laico o clérigo monástico que ha sido elegido como líder por la comunidad del monasterio. Su equivalente en la actualidad es el abad aunque actualmente muchos abades son sacerdotes.
} 


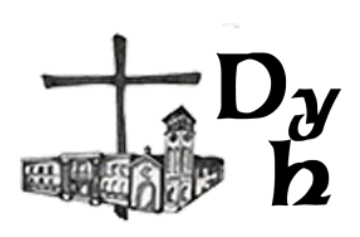

27. Que seamos libres de tener escuelas y seminarios en griego e idiomas eslavo-eclesiásticos en las localidades donde sea más conveniente, y que nuestras imprenta sean libres (por supuesto bajo la supervisión del Metropolitano y de los obispos, para que no se propaguen herejías y nada se imprima sin el conocimiento y consentimiento del Metropolitano y de los obispos).

30. Y si alguien ha sido excomulgado por sus obispos por cualquier ofensa, no lo reciban en la Iglesia romana, sino que, por el contrario, también sea proclamada su excomunión. $\mathrm{Y}$ haremos lo mismo con respecto a los excomulgados de la Iglesia Romana, porque esto es una preocupación común.

31. Y cuando el Señor Dios, por Su voluntad y gracia santa, permita que el resto de nuestros hermanos de la Iglesia Oriental de la tradición griega llegue a la santa unidad con la Iglesia Occidental y posteriormente en esta unión común y con el permiso de la Universal Iglesia deba haber cualquier cambio en las ceremonias y Typicon de la Iglesia griega, vamos a compartir todo esto como personas de la misma religión.

33. Todas estas cosas que nosotros, los infrascritos, deseando la santa concordia para la alabanza del Nombre de Dios y para la paz de la Santa Iglesia de Cristo, hemos dado estos artículos que consideramos necesarios para nuestra Iglesia y para los cuales necesitamos un acuerdo previo y garantías del Santo Padre el Papa y de la Gracia del Rey, nuestro misericordioso Señor, para mayor seguridad, hemos entregado nuestras Instrucciones a nuestros Reverendos hermanos en Dios, padre Hypatius Potij, Obispo Volodymyr de Brest y Padre Cyril Terletsky, Obispo de Lutsk y Ostrih, para que en nuestro nombre y en su propio nombre pidan al Santo Padre el Papa, y también a la Gracia del Rey, nuestro misericordioso Señor, para confirmar y garantizar de antemano todos los artículos que aquí hemos dado por escrito, para que asegurados en cuanto a la fe, los misterios y nuestras ceremonias, podamos llegar a este acuerdo santo con la Iglesia romana sin ninguna violación de nuestra conciencia y la del rebaño de Cristo comprometido con nosotros y de igual manera que otros que todavía vacilan, viendo que conservamos todo lo inviolable, puedan venir más rápidamente a nuestra santa unión, podremos llegar a este sagrado acuerdo con la Iglesia romana.

Dado en el Año de Dios 1595, el mes de junio, el primer día según el Antiguo Calendario.

Mijail, Metropolita de Kiev y Halych y toda la Rus' Hypatius, Obispo de Volodymyr y Brest'. Cyril Terletsky, por la gracia de Dios Exarca y Obispo de Lutsk y Ostrih. Leontius Pelchytsky, por la gracia de Dios Obispo de Pinsk y Turov.

Se agregan los sellos de ocho obispos, incluyendo Gedeon Balaban de L'viv y Dionysius Zbirujski de Kholm. (Treaty Of Brest Document)

El mencionado documento fue presentado a la Santa Sede y después de un profundo estudio y análisis, el documento con las 33 condiciones, fue 
aceptado por el papa Clemente VIII, con algunas pocas modificaciones y algunas ampliaciones de los privilegios, especialmente en lo referente a la elección y consagración del metropolita y de los obispos.

\section{La unión de Brest}

Este día anunciado y santo, el primero después del sábado, real y divino, fiesta de fiestas, solemnidad de solemnidades, en este día glorifiquemos a Cristo por siempre (Irmos, Oda 8, Canon de Pascua. Horologio)

El 23 de diciembre del año 1595, vigilia de la Noche Buena, en el Vaticano, en presencia del papa Clemente VIII y de 33 cardenales, los obispos ucranios, Hipatio Potij y Kerelo Terletskiy, en nombre del metropolita de Kiev Mejailo Rajhoza y de todo el episcopado ucranio, en un ceremonial especial recitaron la profesión de fe católica, sellando con este acto la reunificación de la Iglesia Ucrania con la Sede de Pedro. El papa Clemente VIII, con la Constitución apostólica Magnus Dominus et laudabilis nimis, confirmó la reunificación.

Posteriormente fue redactada la Carta Apostólica Benedictus sit Pater, del 7 de febrero de 1596, con la cual el Sumo Pontífice informa al Metropolita y demás obispos rutenos de la unión felizmente llevada a cabo de toda su Iglesia con la Sede Apostólica.

En esta carta, el Romano Pontífice, después de haber narrado brevemente cuanto en Roma se había hecho en torno a esta causa, y después de haber puesto de relieve con grato ánimo el éxito obtenido finalmente por la misericordia divina, declaró que se podían conservar intactos los usos y los legítimos ritos de la Iglesia rutena.

Por vuestros ritos y ceremonias, que no impiden la integridad de la fe católica y nuestra mutua unión, por el mismo motivo y del mismo modo como fueron permitidos por el concilio florentino, también nosotros permitimos que los retengáis (Theiner, 1860-1864, pág. 251).

En Ucrania esta reunificación fue proclamada oficialmente en un nuevo sínodo convocado para el 16 de octubre de 1596 en Brest-Litovsk junto al río Bug. En este sínodo, participaron no sólo todos los obispos rutenos y muchos otros eclesiásticos, juntamente con los regios legados, sino también los obispos latinos de las diócesis de Lviv, Luck y Kholm, que representaban a la persona del Romano Pontífice, y si bien los obispos de Lviv y de Peremyshl se volvieron atrás del consentimiento dado, sin embargo el 8 de octubre de 1596 fue felizmente confirmada y proclamada la unión de la Iglesia Rutena con la de Roma. 


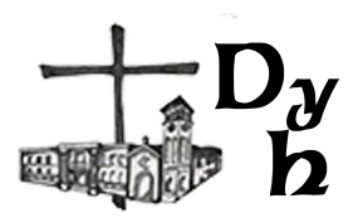

\section{Dificultades luego de la proclamación de la unión}

Pero vino el enemigo y sembró la cizaña en medio del trigo

(Mt 13,25)

Ya sea por ambición de algunos hombres poderosos, sea por enemistades políticas, sea, en fin, por la negligencia tenida en la instrucción y educación del clero y el pueblo en torno a esta materia, se siguieron vehementísimas controversias y continuas desventuras, de modo que parecía deberse temer que esta obra de la unión iniciada con óptimos auspicios fracasara miserablemente.

Que esto no ocurriera desde el principio por las persecuciones e insidias tendidas no sólo por los patriarcados de Constantinopla y de Moscú, sino también por algunos polacos latinos, fue obra sobre todo de los dos Metropolitas Hipatio Potij y José Rutskyj, los cuales, con incansable diligencia, trabajaron por defender y hacer progresar esta causa; y de modo especial se dieron a procurar que los sacerdotes y los monjes se formasen según la sagrada disciplina y las buenas costumbres, y que todos los fieles fuesen educados según los rectos dictámenes de la verdadera fe.

Un ejemplo sobresaliente por llevar adelante la reunificación de la Iglesia ucraniana con el Vicario de Cristo, es el de Josafat Kuncevych. Siendo ya arzobispo de Polotsk, Josafat se consagró totalmente al fortalecimiento de la unión con Roma en su diócesis, con predicaciones, con escritos, con su ejemplo, con extraordinarias penitencias y prolongadas oraciones. Los grandes éxitos obtenidos provocaron la envidia de los adversarios, que conjuraron contra su vida.

\section{San Josafat - Mártir de la Unidad}

Entonces Jesús les dijo: esta noche todos vosotros os apartaréis por causa de mí, pues escrito está: "Heriré al pastor, y las ovejas del rebaño se dispersaran"

(Mt 26,31)

Josafat Juan Kuncevych nació en Ucrania en la ciudad de Volodymyr en el año 1580. A los veintitrés años de edad entró en el monasterio de la Orden de San Basilio en Vilna, consagrándose a Dios en la vida monástica. Después de ejercer por cinco años el diaconado, fue ordenado sacerdote en 1609.

Llegó a ser superior del monasterio y pocos años después fue superior de la Orden Basiliana. En 1617 Josafat fue nombrado obispo auxiliar de Polotsk, sede sufragánea de la metropolía de Kiev, con derecho de sucesión. Tenía sólo 36 años.

La restauración de la jerarquía ortodoxa, en el año 1620, por parte del Patriarcado ortodoxo de Constantinopla, en oposición a la jerarquía ucrania 
unida a Roma, provocó la lucha religiosa, de la cual fue víctima el arzobispo de Polotsk, después de sólo seis años de episcopado.

Mientras el santo hacia la visita pastoral en la ciudad de Vitebsk, también sede episcopal unida a la de Polotsk, los adversarios lo agredieron en su palacio y después de haberle infligido numerosas heridas, lo ultimaron con un golpe de hacha en la cabeza. El martirio tuvo lugar el domingo 12 de noviembre de 1623, cuando el santo se preparaba para la celebración de la Divina Liturgia. Ese domingo, en lugar del Sacrificio del Altar, fue sacrificado el obispo, el cual derramó su sangre para sellar la Unión de la Iglesia Ucrania con Roma. Lo enterraron triunfalmente en la iglesia catedral. Desde ese momento empezaron las gracias y los milagros por la intercesión del mártir. Una de ellas fue la conversión a la Unión del obispo Meletio Smotryckyj, rival ortodoxo de Josafat en la sede de Polotsk y el principal motor de la tragedia.

A los veinte años de la muerte de Josafat, el Papa Urbano VIII lo proclamó beato. Diez años después las reliquias del beato comienzan una larguísima peregrinación, que durará tres siglos, con prolongados períodos de ocultación, hasta que llegaron a Roma como refugio seguro para ser custodiadas y veneradas en el centro de la cristiandad, al lado de la tumba de San Pedro.

Fue el primer santo oriental canonizado en Roma. Lo hizo el Papa Pío IX, en el año 1867, durante las solemnidades del décimo octavo centenario del martirio de los santos Apóstoles Pedro y Pablo. La fiesta litúrgica de san Josafat se celebra, en la Iglesia Universal, el 12 de noviembre, día de su martirio. Es interesante aquí narrar el periplo al cual fueron sometidas las reliquias del santo, lo cual pone en evidencia el odio manifiesto de la iglesia ortodoxa rusa hacia la unidad católica, odio que se ha reavivado nuevamente con la revolución bolchevique de 1918 y el estado comunista ateo y que persiste hasta hoy día.

Al disgregarse el vasto reino polaco, que comprendía, en los tiempos de san Josafat, a Polonia, Ucrania, Bielorrusia y Lituania, se fortalecía contemporáneamente, como una gran potencia política, el imperio de Moscú, con su flamante Patriarcado ortodoxo, heredero de la ortodoxia de Constantinopla. Las continuas luchas internas en el reino polaco provocaron la invasión de los ejércitos rusos y terminaron con la división de sus territorios entre Rusia, Austria y Prusia. La mayor parte de los territorios de Ucrania y Bielorrusia pasaron a la Rusia de Moscú, la cual adoptó una política de destrucción total de la Unión con Roma.

En el año 1653 los ejércitos rusos invadieron los territorios de Polotsk, por lo cual el cuerpo del santo mártir debió ser ocultado durante catorce años. A causa de otra invasión rusa el cuerpo de san Josafat fue retirado de la catedral de Polotsk y llevado a la ciudad de Vilna en el año 1706. Allí fue custodiado en los dominios de los magnates católicos o en los monasterios de los Basilianos, 


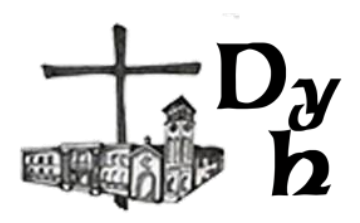

hasta que los rusos se apoderaron de él intentando hacerlo desaparecer para siempre, amurándolo en los sótanos de una iglesia en el año 1873. Las preciosas reliquias fueron encontradas en forma casi milagrosa recién en el año 1916, después que los ejércitos austríacos ocuparon la ciudad de Vilna durante la primera guerra mundial. El cuerpo del santo fue trasladado a Viena, Austria, considerándose la capital austríaca un lugar seguro para las venerables reliquias. Durante la segunda guerra mundial los rusos comunistas ocuparon Viena y el cuerpo de san Josafat debió ser escondido nuevamente, trasladándolo secretamente a Roma en 1949. Por varios años las preciosas reliquias fueron conservadas ocultamente en una de las capillas en la Ciudad del Vaticano. Finalmente en 1963 el cuerpo del Santo Mártir de la Unión fue colocado en la Basílica de San Pedro y expuesto a la veneración de toda la cristiandad.

El 12 de noviembre, fiesta de san Josafat, obispo y mártir, en la liturgia romana, en la oración de la asamblea, se reza:

Reaviva, Señor, en tu Iglesia, el Espíritu de amor, que llevó al obispo san Josafat a inmolarse por su rebaño, y concédenos, por su intercesión, que, fortalecidos por este Espíritu, no temamos dar la vida por nuestros hermanos.

Y en la oración sobre las ofrendas se dice:

Dios misericordioso, derrama tu bendición sobre estos dones, y confírmanos en la fe que san Josafat supo defender al precio de su sangre.

Y finalmente en la oración después de la Comunión:

Te pedimos. Señor, que la participación de esta mesa celestial nos alcance el Espíritu de la fortaleza y de la paz, para que a ejemplo de san Josafat, entreguemos gustosamente nuestra vida para defender el honor y la unidad de la Iglesia (Misal Romano).

Por su parte, la Iglesia Greco-Católica ucraniana, en el día de su fiesta reza:

Glorioso Mártir San Josafat; te manifestaste como antorcha luminosa, y como buen pastor has dado tu vida por las ovejas, convirtiéndote en sacrificio por la santa Unidad. Por tus sufrimientos te hiciste digno del lugar de los santos y de la morada de los ángeles. Ruega a Cristo por nuestra salvación y para que seamos partícipes de los que están a la derecha de su rebaño (Horologio, Vísperas del Obispo Mártir Josafat, Tropario de la fiesta).

Hasta la canonización de san Josafat, todos los santos orientales eran proclamados tales por las mismas Iglesias locales orientales. Su culto se extendía progresivamente también a otras Iglesias orientales $\mathrm{y}$, en caso de grandes santos, a la Iglesia universal. San Josafat fue el primer santo oriental canonizado en Roma, en la Basílica de San Pedro, y por una especial disposición de la Divina Providencia su cuerpo fue solemnemente colocado en dicha Basílica durante el Concilio Vaticano II. 
León XIII, el Papa de la histórica encíclica unionista Orientalium dignitas extendió el culto de san Josafat a toda la Iglesia católica, colocando su fiesta entre las mayores festividades en honor de los santos. Pío XII, además de los grandes elogios al santo mártir, expresados en la encíclica Orientales omnes al conmemorarse, en 1946, los 350 años de la unión de la Iglesia de Kiev con Roma, accedió al pedido de que el cuerpo de san Josafat fuese trasladado de Viena a Roma para salvarlo de la destrucción por parte de los comunistas soviéticos, los cuales ya habían destruido la organización de la Iglesia Católica Ucrania y ahora, al ocupar la capital austríaca, querían destruir el cuerpo del santo, símbolo glorioso de la unión de la Iglesia ucrania con Roma. Juan XXIII, gran amante del Oriente, donde ejerció la mayor parte de su actividad pastoral y diplomática, dispuso la celebración, en la Basílica de San Pedro, de una solemne Divina Liturgia pontifical, participando en ella activamente, en honor de los santos orientales Juan Crisóstomo, doctor de la Iglesia, y Josafat, el Mártir de la Unión, en la vigilia de la grandiosa audiencia concedida a las comisiones preparatorias del Concilio Vaticano II. Con esta celebración el Papa quiso invocar la intercesión de estos dos grandes santos orientales por el feliz éxito del Concilio, que en el pensamiento y en el deseo de Juan XXIII tenía un carácter eminentemente ecuménico, de acercamiento de las iglesias del Oriente y del Occidente.

El mismo Papa accedió amablemente al pedido del Confesor de la fe, Arzobispo Mayor de la Iglesia Católica Ucrania, cardenal Josyf Slipyj, de colocar el cuerpo de san Josafat en la Basílica de San Pedro, hecho que tuvo lugar durante el Concilio Vaticano II y después de la muerte de Juan XXIII, el 25 de noviembre de 1963, con la participación del Papa Pablo VI, de toda la jerarquía ucrania presente en el Concilio y de numerosos obispos de todo el mundo.

\section{Conclusión}

La Iglesia de Cristo es Una, así lo han entendido, luego de haber recorrido un largo camino desde su nacimiento a orillas del Dnipró hasta nuestros días, los fieles ucranios y hoy pueden decir a viva voz "creo en la Iglesia, que es Una, Santa, Católica y Apostólica".

A 422 años de la reunificación la Iglesia Ucraniana, esta se ha mantenido siempre fiel al sucesor de Pedro, a pesar de los embates del enemigo. La sangre de los mártires ha contribuido enormemente a fortalecer la unidad de los cristianos, y el caso de San Josafat lo pone de manifiesto, que no sólo creen en la unidad de la Iglesia, sino que viven y quieren vivir en la Iglesia una e indivisible, tal como la fundó Jesucristo. Las diferencias que surgieron y se desarrollaron entre el cristianismo de Oriente y el de Occidente en el decurso de la historia son, en gran parte, diversidades de origen cultural y de tradiciones y no doctrinal y dogmáticas. En este sentido, la legítima diversidad en cuanto a 


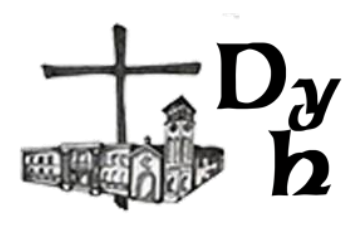

disciplina, liturgia, espiritualidad no se opone de ningún modo a la unidad de la Iglesia, sino que, por el contrario, aumenta su honor y contribuye no poco al cumplimiento de su misión. Es un error grave entender unidad con unificación, católico con latino.

En la Iglesia de Jesucristo -que no es ni latina, ni griega, ni eslava, sino católicano hay discriminación entre sus hijos y todos, -latinos, griegos, eslavos y de otras nacionalidades-, tienen la misma importancia en la mirada de esta Sede apostólica (Sandri, 2017).

Retomo nuevamente las palabras del Patriarca de Antioquia: "Los cristianos se amarían más si se conocieran mejor".

La Unión de Brest sufrió un nuevo golpe entre el 8 y 9 de marzo de 1946, cuando se llevó a cabo la farsa del Sínodo de Lviv, bajo la protección de la policía secreta de Stalin, la NKVD. El objetivo, lograr la "reunificación" de la Iglesia Greco Católica de Ucrania al Patriarcado Soviético de Moscú. Como consecuencia de esto, la Iglesia Greco Católica Ucrania fue prácticamente aniquilada, pocos fueron los que sobrevivieron a estas persecuciones y pudieron contar estos aberrantes hechos. Una figura testimonial de importancia, fue la del Metropolita Josyf Slipyi, quien prefirió décadas de prisión y torturas y no incorporarse al Patriarcado Soviético de Moscú. Esta cuestión podría ser motivo de otra exposición.

Concluimos esta breve presentación con palabras del Papa Juan Pablo II:

La Unión de Brest abrió una nueva página de la historia de aquella Iglesia. Hoy quiere cantar con alegría el himno de gratitud y alabanza a Aquel que, una vez más, la ha llevado de la muerte a la vida, y volverse a poner en camino con nuevo impulso por la senda que marcó el Concilio Vaticano II (Juan Pablo II, 1995).

\section{Bibliografía}

Concilio Vaticano II. (1964). Orientalum Ecclesiarum.

http://www.vatican.va/archive/hist_councils/ii_vatican_council/documents /vat-ii_decree_19641121_orientalium-ecclesiarum_sp.html.

Doroshenko, D. (1962). Historia de Ucrania. Representación Central Ucrania.

Glinka, L. (1986). Breve historia de la Iglesia Ucrania en el milenio de su evangelización. Buenos Aires: Universidad Católica Ucrania San Clemente Papa.

Hazuda, J. (s.f.). IV Centenario de la Unión de Brest (1596-1996). Reunificación de la Iglesia Ucraniana con la Santa Sede. 
